\title{
Low Body Mass Index and Dyslipidemia in Dialysis Patients Linked to Elevated Plasma Fibroblast Growth Factor 23
}

\author{
John R. Montford ${ }^{\mathrm{a}}$ Michel Chonchol ${ }^{\mathrm{a}} \quad$ Alfred K. Cheung ${ }^{\mathrm{c}, \mathrm{d}}$ \\ James S. Kaufman ${ }^{\text {h }}$ Tom Greene ${ }^{e, g}$ William L. Roberts ${ }^{f}$ Gerard Smits $^{\text {a }}$ \\ Jessica Kendrick ${ }^{a, b}$ and the HOST Investigators

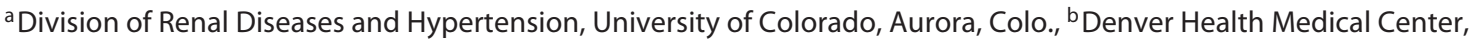 \\ Denver, Colo., ' Renal Section, Medical Service, Veterans Affairs Salt Lake City Healthcare System, Divisions of \\ ${ }^{\mathrm{d}}$ Nephrology and Hypertension and ${ }^{\mathrm{e}} \mathrm{Clinical}$ Epidemiology, and ${ }^{\mathrm{f}}$ Department of Pathology, University of Utah, and \\ ${ }^{g}$ Research Service, Veterans Affairs Salt Lake City Healthcare System, Salt Lake City, Utah, and \\ ${ }^{h}$ Renal Section, Medical Service, Veterans Affairs Boston Healthcare System and Boston University School of \\ Medicine, Boston, Mass., USA
}

\section{Key Words}

Hemodialysis · Fibroblast growth factor 23 - Dyslipidemia .

Body mass index

\begin{abstract}
Background: Fibroblast growth factor 23 (FGF23) has been associated with death in dialysis patients. Since FGF23 shares structural features with FGF19 subfamily members that exert hormonal control of fat mass, we hypothesized that high circulating FGF23 concentrations would be associated with the development of a uremic lipid profile and lower body mass index (BMI). Methods: This study was conducted among 654 patients receiving chronic hemodialysis. C-terminal FGF23 concentrations were measured in stored plasma samples. Linear regression was used to examine the cross-sectional associations of plasma FGF23 concentrations with BMI, total cholesterol (TC), low-density lipoprotein-cholesterol (LDLC), high-density lipoprotein-cholesterol (HDL-C) and triglycerides. Cox proportional hazard models were used to exam-
\end{abstract}

ine the association between FGF23 concentrations and allcause mortality. Results: Participants had a mean age of 60 \pm 11 years and a median (IQR) FGF23 concentration of 4,212 $(1,411-13,816) \mathrm{RU} / \mathrm{ml}$. An increase per SD in $\log _{10} \mathrm{FGF} 23$ was associated with lower BMI $(\beta=-1.11 ; p=0.008)$, TC $(\beta=$ $-6.46 ; p=0.02)$, LDL-C $(\beta=-4.73 ; p=0.04)$ and HDL-C $(\beta=$ $-2.14 ; p=0.03)$; after adjusting for age, gender, race, cardiovascular risk factors, serum albumin, markers of mineral metabolism, and use of lipid-lowering drugs. The association of FGF23 with death was attenuated after adjustment for HDL$\mathrm{C}$ (HR of highest quartile $1.53,95 \% \mathrm{Cl} 1.06-2.20$ compared to lowest quartile). Conclusion: These results indicate that higher plasma FGF23 levels are associated with lower BMI and dyslipidemia in dialysis patients. The association between FGF23 and death may be mediated through unexplored metabolic risk factors unrelated to mineral metabolism.
Copyright $\odot 2013$ S. Karger AG, Basel

\section{KARGER}

E-Mail karger@karger.com

www.karger.com/ajn
(C) 2013 S. Karger AG Basel

0250-8095/13/0373-0183\$38.00/0 


\section{Introduction}

Bone-derived fibroblast growth factor 23 (FGF23) is a phosphaturic hormone that has recently emerged as a key regulator in the body's complex axis of mineral metabolism [1]. In concert with the klotho protein, FGF23 induces urinary phosphate excretion via signaling through the fibroblast growth factor receptor 1 (FGFR1) in renal proximal tubular cells $[2,3]$. By directly inhibiting $1 \alpha$-hydroxylase expression, FGF23 also acts as a counter-regulatory hormone to 1,25-dihydroxyvitamin D $\left(1,25(\mathrm{OH})_{2} \mathrm{D}\right)$ production [1].

Discovery of FGF23 and its biologic effects has refocused attention on the complex dysregulation of mineral metabolism appreciated in patients with chronic kidney disease (CKD). Several epidemiological studies have observed the relationship between declining kidney function and rising FGF23 concentrations $[4,5]$. In addition, increased circulating FGF23 appears to portend adverse outcomes in patients with CKD [5-8]. As a harbinger of poor outcomes, FGF23 joins an already robust group of established metabolic risk factors afflicting patients with end-stage renal disease (ESRD). Much of the focus on FGF23 has attempted to establish a link between the hormone and maladaptive changes in phosphate homeostasis. However, recent investigators have attempted to shed light on novel associations between FGF23 and factors unrelated to mineral metabolism [9].

A recent publication demonstrated that rising FGF23 concentrations correlate with the development of dyslipidemia in patients with normal kidney function [9]. In this study, it was proposed that FGF23 could exert hormonal control on fat mass and glucose metabolism, since it shares structural similarities with the other FGF subfamily members (FGF15/19 and FGF21) that are involved in carbohydrate and lipid metabolism [10]. Given that uremic lipid patterns and lower body mass index (BMI) have been linked with increased mortality in patients with advanced kidney disease requiring chronic dialysis [1113], exploration of a potential interrelationship between FGF23 and these risk factors remains an attractive field for research.

We conducted a cross-sectional study to test the hypothesis that higher FGF23 concentrations are independently associated with dyslipidemia and low BMI in a large cohort of patients requiring chronic dialysis utilizing The Homocysteine in Kidney and End-Stage Renal Disease (HOST) Study infrastructure [14].

\section{Subjects and Methods}

\section{Study Participants}

Details of the HOST study have been described previously [14]. Briefly, the HOST study was a multicenter, prospective, randomized, double-blind, placebo-controlled trial examining the effects of high doses of folic acid, pyridoxine hydrochloride (vitamin $\mathrm{B}_{6}$ ), and cyanocobalamin (vitamin $\mathrm{B}_{12}$ ) on death and cardiovascular events in patients with advanced kidney disease and elevated homocysteine concentrations. The trial enrolled 2,056 participants aged 21 years of age or older with ESRD receiving either maintenance hemodialysis or peritoneal dialysis $(n=751)$, or with an estimated creatinine clearance (calculated by the Cockcroft-Gault formula) $<30 \mathrm{ml} / \mathrm{min}(\mathrm{n}=1,305)$ not requiring chronic dialysis from 36 Veterans Affairs medical centers between September 2001 and October 2003. A plasma homocysteine concentration of $15 \mu \mathrm{mol} / \mathrm{l}$ or higher was also an inclusion criterion.

For the purpose of this analysis, we included only patients with ESRD among the HOST population for the following reasons: (1) we expected less variability in the individual lipid patterns in patients with ESRD as compared with the overall CKD not on dialysis population, (2) we were mostly interested in exploring the association between FGF23 concentrations with BMI and high-density lipoprotein-cholesterol (HDL-C), given that a decrease in BMI and a low HDL-C concentration are important risk factors for allcause mortality in chronic dialysis patients, and (3) FGF23 levels are significantly higher in patients on dialysis as compared with $\mathrm{CKD}$, which may lend an understanding of novel signaling mechanisms in these patients.

\section{Primary Predictor and Outcome}

The primary predictor was circulating FGF23 concentration. Stored ethylenediaminetetraacetic acid (EDTA) plasma samples were drawn from each of the study participants. Measurements of plasma C-terminal FGF23 concentrations were performed using a two-site second-generation enzyme-linked immunosorbent assay (ELISA) kit (Immutopics, San Clemente, Calif., USA) [15]. Analytical measurement range for this assay was 3.0-2,300 RU/ml. The intra-assay coefficients of variations (CVs) were 2.6 and $1.4 \%$ at 32.1 and $299.2 \mathrm{RU} / \mathrm{ml}$ respectively. Inter-assay $\mathrm{CVs}$ were 3.4 and $4.4 \%$ at 32.1 and $299.2 \mathrm{RU} / \mathrm{ml}$, respectively. Laboratory measurements were performed at Associated Regional University Pathologists (ARUP) Laboratories at the University of Utah, with permission from the HOST executive committee and Cooperative Studies Program (CSP) of the Department of Veterans Affairs.

BMI and lipid profile were the outcomes selected for analysis. BMI was calculated in the standard fashion. Lipid measurements were drawn at baseline as fasting samples of serum total cholesterol (TC), low-density lipoprotein-cholesterol (LDL-C), HDL-C, and triglycerides (TG), reported in $\mathrm{mg} / \mathrm{dl}$. Measurements were performed at individual participating VA laboratories using institution-designated parameters.

\section{Other Measurements}

Demographic data, history of hypertension, diabetes, cardiovascular disease, use of lipid-lowering therapies, and dialysis vintage were obtained at enrollment by the original HOST investigators. Serum albumin, calcium, and phosphorus were measured locally using standard techniques. 
Plasma levels of 25-hydroxyvitamin D (25(OH)D), $1,25(\mathrm{OH})_{2} \mathrm{D}$, and intact parathyroid hormone (iPTH) were obtained using stored EDTA plasma samples. Commercial competitive immunoassays were used to measure both $25(\mathrm{OH}) \mathrm{D}$ and $1,25(\mathrm{OH})_{2} \mathrm{D}$ levels (Diasorin, Stillwater, Minn., USA). 25(OH)D level was measured using the LIAISON ${ }^{\circledR} 25 \mathrm{OH}$ Vitamin D chemiluminescent immunoassay. Analytical measurement ranges for the $25(\mathrm{OH}) \mathrm{D}$ assay were $7-150 \mathrm{ng} / \mathrm{ml}$. The intra-assay CVs were 5.6 and $4.5 \%$ at 11 and $28 \mathrm{ng} / \mathrm{ml}$, respectively. The inter-assay CVs were 9.1 and $5.6 \%$ at 16 and $51 \mathrm{ng} / \mathrm{ml}$, respectively. $1,25(\mathrm{OH})_{2} \mathrm{D}$ levels were measured using a double antibody radioimmunoassay with a range of $5-200 \mathrm{pg} / \mathrm{ml}$. The intra-assay CV was 12.6 and $9.7 \%$ at 13 and $45 \mathrm{pg} / \mathrm{ml}$, respectively. The inter-assay CVs were 21.4 and $14.7 \%$ at 25 and $56 \mathrm{pg} / \mathrm{ml}$, respectively. iPTH was measured using a Roche E170 electrochemiluminescent immunoassay with a reference interval of 15-65 pg/ml. The intra- and inter-assay CVs were both less than $5 \%$.

\section{Statistical Analysis}

Subjects were excluded if EDTA plasma samples were not available for FGF23 measurements $(n=97)$ resulting in a final sample of 654 ESRD subjects for the present study. Univariate associations of clinical and demographic variables were compared across quartiles of FGF23 concentrations through the use of the $\chi^{2}$ test for categorical data, ANOVA for continuous variables that are approximately normally distributed, and the Kruskal-Wallis test for skewed continuous variables. Graphical methods, measures of skewness and kurtosis were used to determine the distribution of FGF23 concentrations in the plasma samples. Given the positively skewed distribution of FGF23 concentrations, the values were transformed to the log base of 10 . Spearman correlations were used to investigate the correlation of calcium, phosphorus, $25(\mathrm{OH}) \mathrm{D}$, $1,25(\mathrm{OH})_{2} \mathrm{D}, \mathrm{iPTH}$ and FGF23 concentrations with one another.

The cross-sectional relationship of plasma FGF23 concentrations with BMI and the different components of the lipid profile were assessed with generalized linear regression models. All analyses evaluated FGF23 as a continuous predictor variable after $\log _{10}$ transformation. Covariates were included in the final models if they were significantly correlated with abnormalities of mineral metabolism and were deemed to be biologically plausible. The initial models in all analyses were adjusted for age, gender and race (Model 1). The multivariable-adjusted models further included hypertension, diabetes, history of cardiovascular disease, time on dialysis, serum albumin, calcium, phosphorus, 25(OH)D, $1,25(\mathrm{OH})_{2} \mathrm{D}, \mathrm{iPTH}$ and lipid-lowering drugs (Model 2).

The longitudinal associations between higher FGF23 concentrations with death after adjustment for potential confounders were evaluated using Cox proportional hazards models. The proportional hazards assumptions were confirmed using log-log plots. We considered a priori variables that may be associated with FGF23 concentrations and death as potential confounders in multivariate models, including important clinical variables, cardiovascular risk factors and biochemical measures. In Model 1, we included age, gender, race, smoking status, treatment arm, time on dialysis, history of hypertension, diabetes and cardiovascular disease and albumin. In addition to the variables in Model 1, subsequent models included BMI, TC, LDL-C, HDL-C and TG.

Two-tailed values of $p<0.05$ were considered statistically significant. All statistical analyses were performed with SAS software, version 9.13 (SAS Institute, Cary, N.C., USA).

\section{Results}

\section{Baseline Characteristics}

A total of 654 patients requiring chronic hemodialysis who had plasma FGF23 determinations from the HOST cohort were available for this analysis. Participants had a mean (SD) age of $60 \pm 11$ years and $98 \%$ were male. The majority were Black, smokers and had a history of hypertension, cardiovascular disease, and diabetes. Etiology of chronic dialysis included the following: diabetes (41\%), hypertension (30\%), glomerulonephritis (8\%), polycystic kidney disease (5\%), renovascular disease (2\%) and obstructive nephropathy (2\%). The remaining $12 \%$ had either unknown causes of kidney disease, or causes other than those listed. The median dialysis vintage was 1.4 years.

Participants had a median (IQR) plasma FGF23 concentration of 4,212 (1,411-13,816) RU/ml. Mean serum calcium, phosphorus, iPTH, 25(OH)D, and $1,25(\mathrm{OH})_{2} \mathrm{D}$ levels were $9.1 \pm 0.9 \mathrm{mg} / \mathrm{dl}, 5.6 \pm 1.8 \mathrm{mg} / \mathrm{dl}, 284 \pm 283 \mathrm{pg} /$ $\mathrm{ml}, 18 \pm 22 \mathrm{ng} / \mathrm{ml}$, and $14 \pm 10 \mathrm{pg} / \mathrm{ml}$, respectively.

Baseline characteristics of the study population across FGF23 quartiles are depicted in table 1. Participants in the highest plasma FGF23 quartile tended to be younger, were less likely to have diabetes, used lipid-lowering medications less frequently, spent more days on dialysis, and had HDL-C concentrations than participants in the lowest quartile. In addition, higher plasma FGF23 concentrations were significantly associated with higher serum calcium and phosphorus and plasma iPTH concentrations. No discernable relationship was observed between higher plasma FGF23 with $25(\mathrm{OH}) \mathrm{D}$ and $1,25(\mathrm{OH})_{2} \mathrm{D}$ concentrations. Of note, plasma FGF23 concentrations correlated with serum phosphorus $(r=0.42)$ and plasma iPTH $(\mathrm{r}=0.24)$ concentrations.

\section{FGF23 and BMI}

Participants had a mean BMI of $27 \pm 6$. Using linear regression modeling, we found no relationship between higher FGF23 concentrations and lower BMI in unadjusted analyses and after controlling for patient age, gender and race (Model 1, table 2). However, further adjustments for hypertension, diabetes, history of cardiovasculardisease, dialysisvintage, albumin, calcium, phosphorus, $25(\mathrm{OH}) \mathrm{D}, 1,25(\mathrm{OH})_{2} \mathrm{D}$, iPTH and usage of lipid-lowering drugs (Model 2) yielded a statistically significant association between higher FGF23 and lower BMI $(\beta=$ $-1.11,95 \% \mathrm{CI}-1.91,-0.31 ; \mathrm{p}=0.008)$ per SD increase in $\log _{10}$ FGF23 (table 2). 
Table 1. Baseline characteristics of participants across FGF23 quartiles

\begin{tabular}{|c|c|c|c|c|c|}
\hline \multirow[t]{2}{*}{ Characteristic } & \multicolumn{4}{|l|}{ FGF23, RU/ml } & \multirow[t]{2}{*}{$\mathrm{p}$ value } \\
\hline & $\begin{array}{l}\text { Q1 }(\mathrm{n}=164) \\
\leq 1,411\end{array}$ & $\begin{array}{l}\mathrm{Q} 2(\mathrm{n}=163) \\
1,412-4,207\end{array}$ & $\begin{array}{l}\mathrm{Q} 3(\mathrm{n}=164) \\
4,208-13,816\end{array}$ & $\begin{array}{l}Q 4(n=163) \\
\geq 13,817\end{array}$ & \\
\hline Age, years & $63 \pm 11$ & $62 \pm 12$ & $61 \pm 11$ & $57 \pm 11$ & $<0.0001$ \\
\hline Race, n (\%) & & & & & 0.76 \\
\hline Black & $87(53.0)$ & $85(52.1)$ & $80(48.8)$ & $82(50.3)$ & \\
\hline Hypertension, n (\%) & $155(95)$ & $159(98)$ & $156(95)$ & $154(95)$ & 0.50 \\
\hline Diabetes, $\mathrm{n}(\%)$ & $98(60)$ & $95(58)$ & $83(51)$ & $69(42)$ & 0.006 \\
\hline Cardiovascular disease, n (\%) & $83(51)$ & $80(49)$ & $96(59)$ & $81(50)$ & 0.28 \\
\hline Days on dialysis & $553 \pm 793$ & $862 \pm 1,417$ & $862 \pm 1,231$ & $1,225 \pm 1,366$ & $<0.0001$ \\
\hline BMI & $26.9 \pm 5.3$ & $28.2 \pm 5.6$ & $27.0 \pm 5.6$ & $26.8 \pm 5.6$ & 0.05 \\
\hline $\mathrm{TG}, \mathrm{mg} / \mathrm{dl}$ & $152 \pm 91$ & $167 \pm 119$ & $155 \pm 109$ & $167 \pm 107$ & 0.39 \\
\hline Albumin, g/dl & $3.8 \pm 0.5$ & $3.9 \pm 0.5$ & $3.9 \pm 0.5$ & $3.9 \pm 0.4$ & 0.23 \\
\hline Calcium, mg/dl & $9.0 \pm 0.7$ & $9.0 \pm 1.1$ & $9.2 \pm 0.7$ & $9.4 \pm 0.9$ & $<0.0001$ \\
\hline Phosphorus, mg/dl & $4.7 \pm 1.5$ & $5.4 \pm 1.5$ & $5.6 \pm 1.6$ & $6.5 \pm 2.0$ & $<0.0001$ \\
\hline $25(\mathrm{OH}) \mathrm{D}, \mathrm{ng} / \mathrm{ml}$ & $20 \pm 10$ & $17 \pm 10$ & $17 \pm 10$ & $20 \pm 11$ & 0.30 \\
\hline $1,25(\mathrm{OH})_{2} \mathrm{D}, \mathrm{pg} / \mathrm{ml}$ & $14.4 \pm 8.9$ & $12.1 \pm 6.7$ & $13.9 \pm 9.6$ & $15.6 \pm 12.3$ & 0.05 \\
\hline $\mathrm{iPTH}, \mathrm{pg} / \mathrm{ml}$ & $194 \pm 163$ & $249 \pm 225$ & $273 \pm 238$ & $424 \pm 399$ & $<0.0001$ \\
\hline
\end{tabular}

Values are expressed as means \pm SD unless otherwise specified.

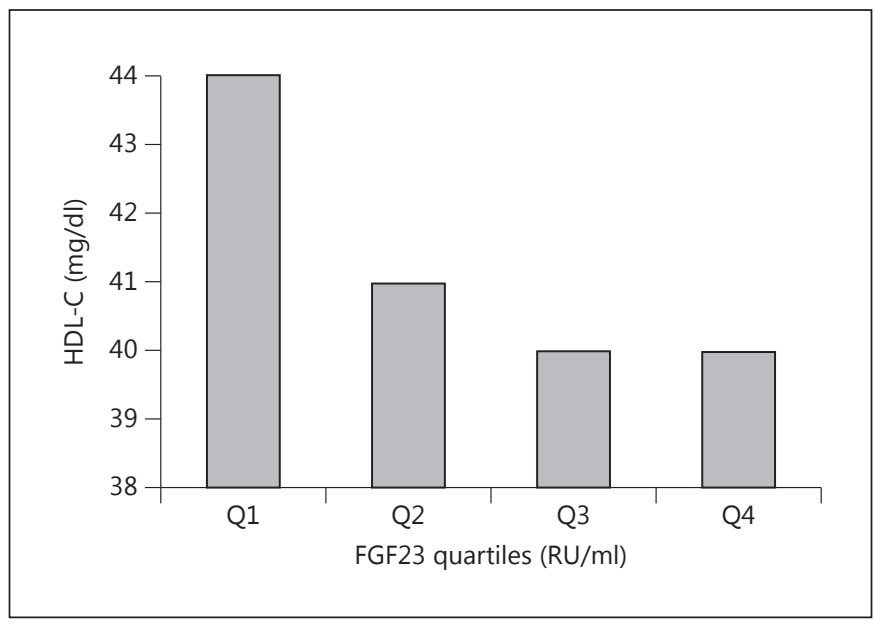

Fig. 1. Plasma HDL-C levels across FGF23 quartiles: $Q 1$ = quartile $1, \leq 1,411 \mathrm{RU} / \mathrm{ml}$, Q2 = quartile 2, 1,412-4,207 RU/ml; Q3 = quartile 3, 4,208-13,816 RU/ml; Q4 = quartile 4, $\geq 13,817 \mathrm{RU} / \mathrm{ml}$.

\section{FGF23 and Dyslipidemia}

The mean serum TC, LDL-C, HDL-C, and TG were $156 \pm 39,84 \pm 32,41 \pm 14$, and $160 \pm 107 \mathrm{mg} / \mathrm{dl}$, respectively. Across higher FGF23 quartiles, study participants had significantly lower serum HDL-C $(\mathrm{p}=0.016)$ (fig. 1$)$. The unadjusted and multivariate relationship between higher plasma FGF23 concentration and the different components of the lipid profile is depicted in table 2. In the age-, gender-, and race-adjusted model (Model 1), we found a statistically significant inverse relationship between FGF23 and HDL-C measurements ( $\beta=-2.24,95 \%$ CI $-3.95,-0.53 ; \mathrm{p}=0.01$ per SD increase in $\log _{10} \mathrm{FGF} 23$ ). Similarly, in the fully adjusted model (Model 2), higher $\log _{10}$ FGF23 concentrations were associated with lower TC $(\beta=-6.46,95 \%$ CI $-11.96,-0.96 ; p=0.02)$, LDL-C $(\beta=-4.73,95 \% \mathrm{CI}-9.23,-0.10 ; \mathrm{p}=0.04)$ and HDL-C $(\beta=-2.14,95 \%$ CI $-4.09,-0.19 ; p=0.03)$. No significant relationship was observed between FGF23 and TG concentrations in unadjusted and adjusted models ( $\mathrm{p}>0.50$ for all). 


\section{Sensitivity Analyses}

To address the clinical relevance of these findings, we examined the relationship between higher FGF23 concentrations with all-cause mortality in the HOST patients receiving chronic dialysis when adjusted for BMI and components of the lipid profile (table 3 ). During a median follow-up of 2.9 years, $262(40 \%)$ patients died from any cause. In Model 1, we initially adjusted for age, gender, race, smoking status, treatment arm, time on dialysis, history of hypertension, diabetes and cardiovascular disease and albumin. Candidate mediators (i.e. BMI, TC, LDL-C, HDL-C and TG) were added individually to the model to determine if they attenuated the association of higher FGF23 concentrations with death. We observed no significant attenuation when BMI, TC, LDL-C, and TG were included in the model. Interestingly, we did notice a moderate attenuation by HDL-C, which diminished the association for death, but the point estimate for hazards among the highest quartile remained 1.5-fold higher than the lowest quartile for death. With the adjustment for HDL-C the association remained statistically significant for all-cause mortality for the highest quartile but became not significant for the second and third FGF23 quartiles.

\section{Discussion}

We report that higher plasma FGF23 concentrations are independently associated in unadjusted and multivariate analyses with lower HDL-C and with lower TC, LDL$\mathrm{C}$ and BMI only after controlling for age, gender, race, cardiovascular risk factors, use of lipid-lowering drugs, albumin, and other markers of mineral metabolism in a cohort of predominantly older male patients requiring chronic dialysis. Interestingly, the association between higher plasma FGF23 concentrations with all-cause mortality was attenuated after adjustment by HDL-C concentrations. These findings suggest that HDL-C may lie on the causal pathway between FGF23 with death in patients requiring chronic dialysis.

Recently, Mirza et al. [9] examined the association between FGF23 concentrations and markers of the metabolic syndrome in two cohorts of predominantly older Caucasian patients from the Osteoporotic Fractures in Men Study (MrOS) and Prospective Investigation of the Vasculature in Uppsala Seniors (PIVUS) study. Lower serum HDL-C and apoA1 along with higher TG were found among patients with higher FGF23 measurements. Interestingly, BMI and measurements of obesity positively
Table 2. Associations between plasma FGF23 concentrations with $\mathrm{BMI}$ and dyslipidemia

\begin{tabular}{llll}
\hline $\begin{array}{l}\text { Predictor: } \\
\log _{10} \text { FGF23 }\end{array}$ & $\beta(95 \%$ CI $)$ & t value & p value \\
\hline BMI & & & \\
$\quad$ Unadjusted & $-0.32(-1.03,0.39)$ & -0.89 & 0.37 \\
$\quad$ Model 1 & $-0.47(-1.19,0.25)$ & -1.27 & 0.20 \\
$\quad$ Model 2 & $-1.11(-1.91,-0.31)$ & -2.68 & 0.008 \\
TC & & & \\
$\quad$ Unadjusted & $-4.72(-9.62,0.18)$ & -1.87 & 0.06 \\
$\quad$ Model 1 & $-4.48(-9.43,0.50)$ & -1.76 & 0.08 \\
$\quad$ Model 2 & $-6.46(-12.0,-0.90)$ & -2.29 & 0.02 \\
LDL-C & & & \\
$\quad$ Unadjusted & $-3.20(-7.28,0.88)$ & -1.53 & 0.12 \\
$\quad$ Model 1 & $-2.99(-7.16,1.17)$ & -1.42 & 0.16 \\
$\quad$ Model 2 & $-4.73(-9.36,-0.10)$ & -2.01 & 0.04 \\
HDL-C & & & \\
$\quad$ Unadjusted & $-2.48(-4.22,-0.74)$ & -2.79 & 0.01 \\
$\quad$ Model 1 & $-2.24(-3.95,-0.53)$ & -2.56 & 0.01 \\
$\quad$ Model 2 & $-2.14(-4.09,-0.19)$ & -2.15 & 0.03 \\
TG & & & \\
$\quad$ Unadjusted & $4.65(-9.27,18.57)$ & 0.66 & 0.51 \\
$\quad$ Model 1 & $2.16(-11.80,16.02)$ & 0.31 & 0.76 \\
$\quad$ Model 2 & $-2.04(-17.54,13.50)$ & -0.26 & 0.80 \\
\hline
\end{tabular}

Model 1: adjusted for age, race, gender.

Model 2: adjusted for Model 1 plus hypertension, diabetes, history of cardiovascular disease, time on dialysis, serum albumin, calcium, phosphorus, $25(\mathrm{OH}) \mathrm{D}, 1,25(\mathrm{OH})_{2} \mathrm{D}$, iPTH levels and lipid-lowering drugs.

correlated with FGF23 in these studies. Overall, the investigators documented a trend towards high FGF23 concentration and presence of the traditionally defined metabolic syndrome.

The observations made amongst our cohort seem somewhat contradictory, as we observed a statistically significant trend towards decreasing BMI among participants in higher FGF23 quartiles. However, the PIVUS and MrOS cohorts included only individuals with normal kidney function (mean estimated glomerular filtration rate of $71 \pm 19$ and $77 \pm 20 \mathrm{ml} / \mathrm{min} / 1.73 \mathrm{~m}^{2}$, respectively) who had significantly lower median FGF23 concentrations $(42.1(25.8,69.4)$ and $42.3(26.3,70.4) \mathrm{pg} / \mathrm{ml}$, respectively) than participants from HOST $(4,212(1,411$, $13,816) \mathrm{RU} / \mathrm{ml}$ ). Of note, in the PIVUS and MrOS cohorts the FGF23 concentrations were measured using an ELISA (Kainos Laboratories International, Tokyo, Japan), which only recognizes the biologically active intact FGF23 and in the HOST participants the assay used only 
Table 3. Associations of plasma FGF23 concentrations with all-cause mortality

\begin{tabular}{|c|c|c|c|c|}
\hline & \multicolumn{4}{|c|}{ FGF23 concentrations, RU/ml } \\
\hline & $\begin{array}{l}\text { Q1 } \\
<1,411\end{array}$ & $\begin{array}{l}\text { Q2 } \\
1,412-4,207\end{array}$ & $\begin{array}{l}\text { Q3 } \\
4,208-13,816\end{array}$ & $\begin{array}{l}\text { Q4 } \\
\geq 13,817\end{array}$ \\
\hline \multicolumn{5}{|c|}{$\begin{array}{l}\text { All-cause mortality } \\
\text { Hazard ratio }(95 \% \text { CI })\end{array}$} \\
\hline $\begin{array}{l}\text { Model } 1 \\
\text { Model } 2 \\
\text { Model } 3\end{array}$ & $\begin{array}{l}1.00 \\
1.00 \\
1.00\end{array}$ & $\begin{array}{l}1.50(0.95-2.21) \\
1.53(0.97-2.28) \\
1.36(0.94-1.98)\end{array}$ & $\begin{array}{l}1.65(1.10-2.46) \\
1.66(1.14-2.41) \\
1.42(0.96-2.09)\end{array}$ & $\begin{array}{l}1.72(1.18-2.50) \\
1.69(1.16-2.46) \\
1.53(1.06-2.20)\end{array}$ \\
\hline
\end{tabular}

Model 1: age, gender, race, smoking status, treatment arm, time on dialysis, history of hypertension, diabetes and cardiovascular disease and albumin.

Model 2: Model $1+$ BMI, TC, LDL-C and TG.

Model 3: Model $2+$ HDL-C.

detected the C-terminal FGF23 $[8,9]$. Although it has been shown that both assays correlate well $(\mathrm{r}=0.74, \mathrm{p}<$ 0.001 ) in chronic dialysis patients, it is plausible that the different results observed across cohorts could be explained by the differences in the assay [6].

In regard to anthropomorphic measurements, patients on maintenance dialysis have a markedly dissimilar body mass phenotype compared with age- and sexmatched controls in the general population [16]. Decreased BMI has been shown to correlate with poor outcomes in patients requiring chronic dialysis $[12,14,16-$ 18]. A survival advantage among the obese is not observed in patients with normal kidney function, but is observed in patients requiring dialysis $[18,29]$. The exact mechanism of this 'reverse epidemiological' paradox remains a mystery, but many implicate a combination of protein energy malnutrition and altered inflammatory cascades among other causative factors.

More relevant to our data are observations made in a separate study by Ashikaga et al. [20], comparing the impact of FGF23 concentrations on lipids and carotid intima medial thickness in a subset of 196 ESRD patients requiring chronic hemodialysis. The authors discovered a negative relationship between FGF23 and serum TC, non-HDL-C, and maximal carotid intima medial thickness. No relationship was appreciated between FGF23 with HDL-C or LDL-C. Surprisingly, the authors noted improvement in nutritional status as measured by the geriatric nutritional risk index and increased BMI across higher FGF23 tertiles. We describe similar results with regard to TC, but also observed a significant inverse association between FGF23 and BMI, LDL-C, and HDL-C concentrations that persisted after multivariate analysis.
There are several potential explanations for these disparate results. We were able to include substantially more patients from the HOST study $(\mathrm{n}=654)$ compared with the study by Ashikaga et al. $(n=196)$, thus improving the statistical power of our results. Those authors also report on non-fasting lipid profiles, which is not the ideal method of obtaining these measurements. Furthermore, investigators in that study plotted nutritional indices and BMI measurements against FGF23 changes in unadjusted analysis and the investigators did not attempt to control for several potential known confounders of these nutritional indexes. Moreover, lack of control for vitamin D in the report's statistical analysis weakens the interpretability of the obtained lipid values. Evidence currently supports a significant association between $1,25(\mathrm{OH})_{2} \mathrm{D}$ with lipid metabolism in patients with CKD [21, 22]. In our study, we were able to measure each participant's stored fasting $25(\mathrm{OH}) \mathrm{D}$ and $1,25(\mathrm{OH})_{2} \mathrm{D}$ concentrations, and incorporate these into the analysis, thus strengthening our reported associations.

There is currently a paucity of evidence to support a biochemical mechanism by which FGF23 might control lipid regulation. An attractive theory is that FGF23 can signal through multiple FGFRs previously thought limited to other FGF19 subfamily members. In fact, FGF23 is closely related in structural homology to both FGF15/19 and FGF21 [10]. FGF-15/19 signaling is primarily implicated in bile acid metabolism and gallbladder filling, while experimental data supports a role for FGF21 in regulation of lipolysis [23]. Though FGF23 has been shown to signal primarily through FGFR1c, $3 \mathrm{c}$, and $4 \mathrm{c}$ in the kidney, parathyroid gland, and choroid plexus of the brain [24], in vitro studies demonstrate that FGF23 can signal 
through multiple FGFRs [25]. Additionally, patients with advanced CKD have concentrations of FGF23 that are severalfold higher than those appreciated in the general population $[4,5]$. The potential biochemical effects of such high circulating FGF23 concentrations have not been fully elucidated. Therefore, it remains plausible that FGF23 has as yet to be determined actions unrelated to its established role in regulating mineral metabolism in these patients.

This study has several strengths worth mentioning. A robust number of patients were enrolled from the HOST trial, with similar baseline characteristics to the general dialysis population. We were also able to measure and adjust for several potential known confounders, strengthening the analysis. In addition, all of the stored plasma samples were performed in one laboratory decreasing the chance of variability in the interpretation of results. Our data is limited by the fact that it is a cross-sectional analysis of one plasma sample in time. Thus we cannot prove a direction to the association between FGF23 with dyslipidemia and lower BMI. Participants were on average older, and the majority were Black males, therefore, caution must be exercised before extrapolating our results to the general population. Among the HOST participants, we did not have access to the measurements of patient's truncal fat mass, lean muscle mass, and protein intake, which would have potentially yielded more compelling data.
Additionally, we were not able to control for administration of vitamin $\mathrm{D}$ analogues.

In conclusion, we report an independent association between higher FGF23 concentrations with lipid disturbances and lower BMI in a cohort of male patients requiring chronic dialysis. Our study should spark interest into research aimed at further elucidating additional mechanisms by which high FGF23 concentrations result in poor outcomes in patients with advanced CKD.

\section{Acknowledgements}

The research reported in this study was supported by the CSP of the Department of Veterans Affairs Office of Research and Development and the HOST Executive (Rex L. Jamison, Pamela Hartigan, James Kaufman, David S. Goldfarb, Stuart R. Warren, Peter D. Guarino, and J. Michael Gaziano). A full list of Veterans Affairs HOST Site Investigators and institutions can be found at http:// www.ncbi.nl.gov/pubmed/17848650. Additional support came from the National Institute of Diabetes and Digestive and Kidney Disease grants K23 DK087859-01A1, R01 DK081473 and an AMGEN fellowship grant. We are also grateful to William E. Owen from the ARUP Institute for Clinical and Experimental Pathology for assistance with the plasma FGF23 assay.

\section{Disclosure Statement}

The authors have no conflicts of interest to disclose.

\section{References}

1 Shimada T, Hasegawa H, Yamazaki Y, Muto T, Hino R, Takeuchi Y, Fujita T, Nakahara K, Fukumoto S, Yamashita T: FGF-23 is a potent regulator of vitamin $\mathrm{D}$ metabolism and phosphate homeostasis. J Bone Miner Res 2004;19: 429-435.

- Prié D, Ureña Torres P, Friedlander G: Latest findings in phosphate homeostasis. Kidney Int 2009;75:882-889.

3 Kurosu H, Kuro-O M: The Klotho gene family as a regulator of endocrine fibroblast growth factors. Mol Cell Endocrinol 2009; 299:72-78.

-4 Larsson T, Nisbeth U, Ljunggren O, Juppner $\mathrm{H}$, Jonsson K: Circulating concentration of FGF-23 increases as renal function declines in patients with chronic kidney disease, but does not change in response to variation in phosphate intake in healthy volunteers. Kidney Int 2003;64:2272-2279.

5 Gutiérrez OM, Januzzi JL, Isakova T, Laliberte K, Smith K, Collerone G, Sarwar A, Hoffmann U, Coglianese E, Christenson R, Wang TJ, deFilippi C, Wolf M: Fibroblast growth factor 23 and left ventricular hyper- trophy in chronic kidney disease. Circulation 2009;119:2545-2552.

6 Gutierrez OM, Mannstadt M, Isakova T, Rauh-Hain JA, Tamez H, Shah A, Smith K, Lee $\mathrm{H}$, Thadhani R, Juppner H, Wolf M: Fibroblast growth factor 23 and mortality among patients undergoing hemodialysis. N Engl J Med 2008;359:584-592.

7 Isakova T, Xie H, Yang W, Xie D, Anderson AH, Scialla J, Wahl P, Gutierrez OM, Steigerwalt S, He J, Schwartz S, Lo J, Ojo A, Sondheimer J, Hsu CY, Lash J, Leonard M, Kusek JW, Feldman HI, Wolf M; Chronic Renal Insufficiency Cohort (CRIC) Study Group: Fibroblast growth factor 23 and risks of mortality and end-stage renal disease in patients with chronic kidney disease. JAMA 2011;305: 2432-2439.

-8 Kendrick J, Cheung AK, Kaufman J, Greene T, Roberts WL, Smits G, Chonchol M; HOST Investigators: Elevated FGF-23 associates with death, cardiovascular events and dialysis initiation. J Am Soc Nephrol 2011;22:1913-1922.

-9 Mirza MA, Alsiö J, Hammarstedt A, Erben RG, Michaelsson K, Tivesten A, Marsell R,
Orwoll E, Karlsson MK, Ljunggren O, Mellstrom D, Lind L, Ohlsson C, Larsson TE: Circulating fibroblast growth factor-23 is associated with fat mass and dyslipidemia in two independent cohorts of elderly individuals. Arterioscler Thromb Vasc Biol 2011;31:219227.

10 Fukumoto S: Actions and mode of actions of FGF19 subfamily members. Endocr J 2008;55: 23-31.

11 Kwan BC, Kronenberg F, Beddhu S, Cheung AK: Lipoprotein metabolism and lipid management in chronic kidney disease J Am Soc Nephrol 2007;18:1246-1261.

12 Kopple JD, Zhu X, Lew NL, Lowrie EG: Body weight-for-height relationships predict mortality in maintenance hemodialysis patients. Kidney Int 1999;56:1136-1148.

13 Leavey SF, McCullough K, Hecking E, Goodkin D, Port FK, Young EW: Body mass index and mortality in 'healthier' as compared with 'sicker' haemodialysis patients: results from the Dialysis Outcomes and Practice Patterns Study (DOPPS). Nephrol Dial Transplant 2001;16:2386-2394. 
14 Jamison RL, Hartigan P, Kaufman JS, Goldfarb DS, Warren SR, Guarino PD, Gaziano JM; Veterans Affairs Site Investigators: Effect of homocysteine lowering on mortality and vascular disease in advanced chronic kidney disease and end-stage renal disease: a randomized controlled trial. JAMA 2007;298: 1163-1170.

15 Jonsson KB, Zahradnik R, Larsson T, White KE, Sugimoto T, Imanishi Y, Yamamoto T, Hampson G, Koshiyama H, Ljunggren $\mathrm{O}$, Oba K, Yang IM, Miyauchi A, Econs MJ, Lavigne J, Juppner H: Fibroblast growth factor 23 in oncogenic osteomalacia and X-linked hypophosphatemia. N Engl J Med 2003;348: 1656-1663.

16 Kopple JD: Nutritional status as a predictor of morbidity and mortality in maintenance dialysis patients. ASAIO J 1997;43:246-250.

$\checkmark 17$ Leavey SF, Strawderman RL, Jones CA, Port FK, Held PJ: Simple nutritional indicators as independent predictors of mortality in hemodialysis patients. Am J Kidney Disease 1998;6: 997-1006.
18 Kamyar KZ, Abbot KC, Salahudeen AK, Kilpatrick RD, Horwich TB: Survival advantages of obesity in dialysis patients. Am J Clin Nutr 2005;81:543-554.

19 Yan LL, Daviglus ML, Liu K, Stamler J, Wang R, Pirzada A, Garside DB, Dyer AR, Van Horn L, Liao Y, Fries JF, Greenland P: Midlife body mass index and hospitalization and mortality in older age. JAMA 2006;295:190198.

20 Ashikaga E, Honda H, Suzuki H, Hosaka N, Hirai Y, Sanada D, Nakamura M, Nagai H, Matsumoto K, Kato N, Mukai M, Watanabe M, Takahashi K, Shishido K, Akizawa T: Impact of fibroblast growth factor 23 on lipids and atherosclerosis in hemodialysis patients. Ther Apher Dial 2010;14:315-322.

21 Jorde R, Grimnes G: Vitamin D and metabolic health with special reference to the effect of vitamin D on serum lipids. Prog Lipid Res 2011;50:303-312.
22 Wang XX, Jiang T, Shen Y, Santamaria H, Solis N, Arbeeny C, Levi M: Vitamin D receptor agonist doxercalciferol modulates dietary fatinduced renal disease and renal lipid metabolism. Am J Physiol Ren Physiol 2011; 300:F801-F810.

23 Yamashita T, Yoshioka M, Itoh N: Identification of a novel fibroblast growth factor, FGF23 , preferentially expressed in the ventrolateral thalamic nucleus of the brain. Biochem Biophys Res Commun 2000;277:494-498.

24 Kurosu H, Choi M, Ogawa Y, Dickson AS, Goetz R, Eliseenkova AV, Mohammadi M, Rosenblatt KP, Kliewer SA, Kuro-O M: Tissue-specific expression of betaKlotho and fibroblast growth factor (FGF) receptor isoforms determines metabolic activity of FGF19 and FGF21. J Biol Chem 2007;282:2668726695.

25 Liu S, Quarles LD: How fibroblast growth factor 23 works. J Am Soc Nephrol 2007;18: 1637-1647. 